\title{
Changing self-esteem in children and adolescent: a roadmap for future interventions
}

Citation for published version (APA):

Bos, A., Muris, P. E. H. M., Mulkens, S., \& Schaalma, H. P. (2006). Changing self-esteem in children and adolescent: a roadmap for future interventions. Netherlands Journal of Psychology, 62, 26-33. https://doi.org/10.1007/BF03061048

Document status and date:

Published: 01/01/2006

DOI:

10.1007/BF03061048

Document Version:

Publisher's PDF, also known as Version of record

Document license:

Taverne

Please check the document version of this publication:

- A submitted manuscript is the version of the article upon submission and before peer-review. There can be important differences between the submitted version and the official published version of record.

People interested in the research are advised to contact the author for the final version of the publication, or visit the DOI to the publisher's website.

- The final author version and the galley proof are versions of the publication after peer review.

- The final published version features the final layout of the paper including the volume, issue and page numbers.

Link to publication

\footnotetext{
General rights rights.

- You may freely distribute the URL identifying the publication in the public portal. please follow below link for the End User Agreement:

www.umlib.nl/taverne-license

Take down policy

If you believe that this document breaches copyright please contact us at:

repository@maastrichtuniversity.nl

providing details and we will investigate your claim.
}

Copyright and moral rights for the publications made accessible in the public portal are retained by the authors and/or other copyright owners and it is a condition of accessing publications that users recognise and abide by the legal requirements associated with these

- Users may download and print one copy of any publication from the public portal for the purpose of private study or research.

- You may not further distribute the material or use it for any profit-making activity or commercial gain

If the publication is distributed under the terms of Article $25 \mathrm{fa}$ of the Dutch Copyright Act, indicated by the "Taverne" license above, 


\title{
Changing self-esteem in children and adolescents: a roadmap for future interventions
}

\author{
Arjan E.R. Bos • Peter Muris • Sandra Mulkens • Herman \\ P. Schaalma
}

\begin{abstract}
Self-esteem is an important construct that is related to academic achievement, social functioning and psychopathology in children and adolescents. Therefore, it is not surprising that many interventions have tried to change levels of self-esteem in this population. In this article a theoretical overview of self-esteem in children and adolescents is presented, in which recent research on different aspects of self-esteem will be discussed. Subsequently, research on treatment and primary prevention programs to change self-esteem in children and adolescents is reviewed. It is argued that self-esteem interventions will be more effective when they are theory- and evidence-based and tailored to the specific needs of different target groups. Finally, a roadmap for the development of theory- and evidence-based interventions is presented and some recommendations for future selfesteem interventions are provided. (Netherlands Journal of Psychology 2006, 62, 26-33.)
\end{abstract}

Self-esteem is a central concept that is related to academic achievement, social functioning and psychopathology of children and adolescents. With respect to academic achievement, various studies indicate that children with low self-esteem are less successful at school (Mann, Hosman, Schaalma, \& De Vries, 2004). For social functioning, research has demonstrated that

Arjan E.R. Bos*, * Erasmus University Rotterdam and Open University of the Netherlands** Erasmus University,

Rotterdam*** Maastricht University,

MaastrichtCorrespondence to: Dr Arjan Bos, Institute of Psychology, Erasmus University Rotterdam, PO Box 1738, NL 3000 DR Rotterdam. E-mail: bos@fsw.eur.nlSubmitted 23 March 2006; revision accepted 8 June 2006. children with low self-esteem are usually less accepted by their peers (e.g., Donders \& Verschueren, 2004). Finally, many studies have shown that low self-esteem is related to child psychopathology, including anxiety (Beck, Brown, Steer, Kuyken, \& Grisham, 2001; Muris, Meesters, \& Fijen, 2003), depression (Harter, 1993; Mann et al., 2004) and eating pathology (e.g. Muris, Meesters, Van de Blom, \& Mayer, 2005; Stice, 2002). There is still much debate about the relation between self-esteem and externalising problems such as aggression, antisocial behaviour and delinquency. Whereas some researchers have argued that externalising problems are related to high self-esteem and result from threatened egotism (e.g., Baumeister, Smart, \& Boden, 1996), others have found a strong relation between low self-esteem and externalising problems (Donnellan, Trzesnieuwski, Robins, Moffitt, \& Caspi, 2005).

Given the importance of self-esteem in the development and general functioning of youths, it is not surprising that many interventions have been developed to change self-esteem in these young people. This article reviews research on treatment and primary prevention programs to change self-esteem in youths. It is argued that theory- and evidence-based self-esteem interventions will be most successful in changing self-esteem in children and adolescents. A systematic approach for such interventions will be presented.

\section{Self-esteem in children and adolescents}

Self-esteem refers to an overall evaluation of one's worth or value as a person (Harter, 2003). Global self-esteem is distinguished from domain-specific self-esteem, such as scholastic competence, athletic competence, peer 
likeability, physical appearance and behavioural conduct (Harter, 1999; 2003). The ability to make global selfevaluations does not occur until mid-childhood. Younger children are able to judge their ability in specific domains, but they are not able to make overall judgments about their self-worth (Harter, 1999). In adolescence, self-evaluations become more differentiated and other domains become relevant, such as close friendship, romantic appeal, and job competence (Harter, 2003).

In general, people are motivated to maintain high levels of self-esteem and to defend their self-esteem when it comes under threat (Pyszczynski, Greenberg, Solomon, Arndt \& Schimel, 2004). According to Terror Management Theory, people strive for positive self-evaluations, because self-esteem provides a buffer against death-related anxiety (Greenberg, Pyszczynski, \& Solomon, 1986). Several studies have provided empirical evidence for the anxiety-buffering properties of self-esteem (see Pyszczynski et al., 2004). According to Sociometer Theory (Leary \& Baumeister, 2000), however, selfesteem serves as a monitor of social belongingness. It tells us how valued and socially accepted we are in the eyes of others. Children easily adopt the views that others, such as caregivers and other relevant adults, have about them (Leary \& MacDonald, 2003). Thus, parents who are approving, responsive and nurturing are likely to build high levels of self-esteem in their children, whereas disapproving, unresponsive and uninterested parents may break down self-esteem levels in their children. In adolescence the link between parenting style and self-esteem is still quite strong, but approval of peers becomes the most important predictor of self-esteem. Sociometer Theory acknowledges the importance of competence related beliefs for high self-esteem (e.g., academic achievement or athletic competence), but argues that the impact of these beliefs on self-esteem is mediated by perceived relational value (Leary \& MacDonald, 2003).

\section{Development of global self-esteem in childhood and adolescence}

Whereas the level of global self-esteem is generally relatively high during childhood, it drops dramatically when children enter adolescence (Robins, Trzesniewski, Tracy, Gosling, \& Potter, 2002; Major, Barr, Zubek, \& Babey, 1999). The enormous decrease in global self-esteem during adolescence can be attributed to significant changes that take place during the transition from childhood to adolescence. Clearly, adolescence is a stressful developmental stage with marked biological, cognitive, social, psychological, and academic changes
(Finkenauer, Engels, Meeus, \& Oosterwegel, 2002; Robins et al., 2002). First, girls and boys become reproductively mature in early adolescence. Second, they acquire the capacity of formative thinking. Third, adolescents spend less time with their families, and friendships and romantic or sexual relationships become increasingly important. Therefore, adolescents become vulnerable to feelings of social inadequacy. Finally, they experience the transition from primary to secondary school.

Research on gender differences in childhood selfesteem has yielded inconsistent results. Some studies have indicated that boys have a higher self-esteem than girls (Kling, Hyde, Showers, \& Buswell, 1999), whereas other studies found no gender differences (Major et al., 1999; Robins et al., 2002). During adolescence, however, the picture seems clear. Most studies have demonstrated that self-esteem decreases more sharply in adolescent girls than in adolescent boys (Robins et al., 2002).

\section{Different aspects of self-esteem}

For a long time many researchers have focused on the general level of self-esteem in youngsters. In the past ten years, however, research has identified various important aspects of self-esteem (Harter, 2003; Kernis, 2002).

One important aspect is self-esteem stability. Unstable self-esteem refers to short-term fluctuations in one's selfesteem and reflects fragile feelings of self-worth (Kernis \& Goldman, 2003). Correlations between level of selfesteem and self-esteem stability are generally low, suggesting that these are independent manifestations of selfesteem. Further, research has demonstrated that selfesteem level and self-esteem stability are both related to psychological well-being (Kernis \& Goldman, 2003; Paradise \& Kernis, 2002). Self-esteem stability is low during childhood and early adolescence, but becomes more stable throughout adolescence (Trzesniewski, Donnellan, \& Robins, 2003). Interestingly, boys and girls do not differ in their self-esteem stability in childhood or adolescence (Trzesniewski et al., 2003).

Another concept that is closely related to self-esteem stability is contingent self-esteem, which refers to the extent to which self-esteem is contingent upon outcomes and achievements (Kernis, 2002). People with contingent self-esteem are preoccupied by their performance and by the evaluations of others. Their levels of self-esteem fluctuate depending on success or failure. Contingent selfesteem also reflects fragile self-esteem: people with contingent self-esteem continuously have to be successful in order to feel good about themselves. A distinction can be made between global contingent self-esteem and domainspecific contingent self-esteem. People with domain- 
specific contingent self-esteem base their self-esteem on outcomes and achievements in certain domains, such as academics, approval from others, appearance, and sports (Crocker \& Wolfe, 2001; Jansen \& Vonk, 2005). It is conceivable that domain-specific contingent self-esteem (e.g., appearance) is related to psychopathology in children or adolescents (e.g., eating disorders), but most research on contingent self-esteem has been conducted among students or adults.

A final important aspect of self-esteem is implicit selfesteem. Many researchers use self-report scales to measure self-esteem in children and adolescents (see for an overview: Butler \& Gasson, 2005). However, these measures of explicit self-esteem measure conscious perceptions of the self. Implicit self-esteem is a non-conscious form of self-esteem that is based on automatic self-evaluative processes (Dijksterhuis, 2004; Greenwald \& Banaji, 1995). It is an automatic attitude towards the self that influences self-evaluations and evaluations of self-relevant objects (Baccus, Baldwin, \& Packer, 2004; Greenwald \& Farnham, 2000). Implicit and explicit selfesteem are generally weakly correlated, suggesting that both forms of self-esteem reflect independent processes (Baccus et al., 2004; Hoffman, Gawronski, Gschwender, Le \& Schmitt, 2005). Implicit self-esteem is related to lower levels of aspiration after failure and seems a better predictor of anxiety during a very personal interview. In addition, people with high levels of explicit self-esteem and low levels of implicit self-esteem seem to have greater defensiveness and higher levels of narcism (see Baccus et al., 2004; Dijksterhuis, 2004). Recent research indicates that early childhood experiences with parents affect levels of implicit self-esteem later in life (DeHart, Pelham, \& Tennen, 2006). Individuals who had nurturing parents reported relatively high implicit self-esteem, whereas subjects with overprotecting parents displayed relatively low levels of implicit self-esteem. Despite the importance to distinguish explicit from implicit selfesteem and in spite of the unique impact of implicit selfesteem on psychological outcomes, no studies have as yet examined implicit self-esteem in children and adolescents.

\section{Determinants of self-esteem in children and adolescents}

According to Harter, two factors play an important role in the development and maintenance of self-esteem in children and adolescents: (1) perceived competence in areas of importance, and (2) the experience of social support (Harter, 1999). Domains of perceived competence not only have a direct impact on self-esteem, but also influence approval and support of parents and peers.
That is, good academic competence and behavioural conduct elicit approval and support of parents, whereas good physical appearance, relationships to peers, and athletic competence result in approval and support of peers (Harter, 2003).

Many children and adolescents maintain a positive view of themselves by achieving success in domains of perceived competence (Crocker \& Park, 2003). For example, boys who are relatively good at football may play football more frequently and may invest more time in training. As a consequence, their football skills increase even further and their self-esteem remains high. However, youths are not always capable of achieving success, which makes them engage in strategies to protect, maintain or enhance their self-esteem levels. In the face of failure, children and adolescents may use strategies such as downward social comparison (comparing themselves with others who are worse off) and external attributions (attributing failure to external causes), or they may reduce the importance of the domain on which they fail to achieve success (Crocker \& Park, 2003).

\section{Changing self-esteem in children and adolescents: where are we now?}

According to Harter (1999), self-esteem interventions should be directed at its cognitive and social determinants. Four strategies can be identified that are directed at the cognitive determinants. First, self-esteem interventions should reduce discrepancies between aspirations and perceived competence. One way is to improve skills in areas in which there are large discrepancies, which may in turn lead to enhanced perceptions of competence. Another way is to highlight the importance of areas in which the child is skilful and to discount the ones in which he/she is unsuccessful. Second, self-esteem interventions for older children and adolescents could attempt to encourage relatively accurate self-evaluations. However, the enhancement of perceptions of competence in youths with low selfworth is rather difficult as they generally tend to seek feedback that confirms their self-concept and are thus relatively resistant to attempts to alter their self-perceptions. Third, self-esteem interventions should assess the potential for change in the valence of self-representations. For example, during the transition from primary to secondary school, young people become vulnerable and self-esteem levels tend to drop drastically. This seems to be an appropriate developmental period for primary prevention interventions and attempts to increase self-esteem of those youngsters who have low 
self-esteem. Fourth, self-esteem interventions should also pay attention to individual's own theories about the causes of their low self-esteem. In general, children and adolescents with low self-esteem tend to attribute their failures internally. One strategy is to cognitively reframe children's attributions, resulting in global, stable, internal attributions for one's successes.

Harter (1999) also suggests two strategies that are directed at social factors influencing youths' selfesteem. First, self-esteem interventions should try to increase approval support. If the perception of social support is unrealistic, interventions should focus on developing a more realistic appreciation of the support provision. For children and adolescents who experience lack of support from their parents, therapeutic interventions (e.g., family therapy) focusing on the interpersonal relationship between youngsters and parents may be helpful. Furthermore, success in the domains of academic competence and behavioural conduct may also result in more approval support from parents. For children and adolescents who experience lack of support from their peers, improving skills in domains that are valued by peers may be an option (e.g., attractiveness, athletic performance, interpersonal qualities). Children who are socially rejected could follow a social skills program or may ultimately be removed from their unsupportive peer group and placed in another more supportive peer group. Second, self-esteem interventions should focus on the internalisation of the positive opinions of others. One strategy to foster internalisation is to help children and adolescents to establish personal ideals for which they strive (as opposed to striving for the ideals of others). Another strategy is to underline children's role in producing positive outcomes in tasks and to emphasise that they must feel proud of themselves.

Self-esteem interventions can be divided into treatment programs and primary prevention programs. Treatment programs focus on enhancing self-esteem among those who already have low self-esteem, whereas primary prevention programs target non-clinical populations. Cognitive-behavioural therapy seems to be particularly effective in changing self-esteem (Emler, 2001). This type of intervention focuses on identifying dysfunctional beliefs and changing them into more realistic beliefs, in combination with behaviour modification techniques. Obviously, treatment approaches should target the determinants of low self-esteem, which were described in the previous paragraph. These findings suggest that self-esteem enhancement requires the formation and acceptance of realistic goals in domains that are personally relevant, and a supportive social environment (Harter, 1999; Mann et al., 2004). For example, if a child lacks competence in important domains, the therapist could try to enhance competence or to lower the importance of this area for a person's selfworth (Harter, 1999). If a child lacks approval from others, the therapist should work on factors related to social functioning.

Most primary prevention programs targeting children and adolescents have focused on enhancing global selfesteem. Often, these interventions do not exclusively focus on self-esteem, but also on reducing problematic behaviour or improving functioning in various areas (Haney \& Durlak, 1998). Many self-esteem interventions are school-based programs, which can reach a large number of children and may be cost-effective if they become part of the regular curriculum and are delivered by teachers (Haney \& Durlak, 1998). There is a huge variety of primary prevention programs that focus on self-esteem enhancement in children and adolescents (Emler, 2001). For example, some interventions focus on developing competencies by training certain skills, whereas others aim at changing attitudes and perceptions. Since programs also vary considerably in length, intensity and form and generally consist of multiple components, it is hard to identify the determinants of program effectiveness (Emler, 2001).

Haney and Durlak (1998) conducted a meta-analysis to evaluate the effectiveness of interventions to change self-esteem in children and adolescents. Their review of 116 studies revealed a modest effect $(0.27)$ on measures of self-esteem and self-concept. In general, programs were successful in enhancing youths' self-esteem and they seemed to bring about positive changes in behavioural, personality and academic functioning. However, this meta-analysis also revealed that the effectiveness of the intervention critically depended on the type and focus of the intervention and on the extent to which these programs were theory- and evidence-based. First, treatment programs were more effective than primary prevention programs. An explanation is that selfesteem levels of clinically referred children and adolescents are often much lower than those of youngsters in the general population, and that therefore an intervention may yield larger effects. Second, interventions that focused specifically on enhancing self-esteem were more effective than interventions targeting other aspects such as behaviour or social skills. Third, theory- or evidence-based programs produced better effects than programs lacking such theoretical or empirical basis. Altogether, these findings suggest that self-esteem interventions can be more successful if they focus exclusively on self-esteem and its determinants and when such programs are theory- and evidence-based (see also WHO, 2004). 
Figure 1 The six steps of Intervention Mapping. Reprinted from Bartholomew, L.K., Parcel, G.S., Kok, G., \& Gottlieb, N.H. (2006). Planning health promotion programs: an Intervention Mapping approach. San Francisco, CA: Jossey-Bass.

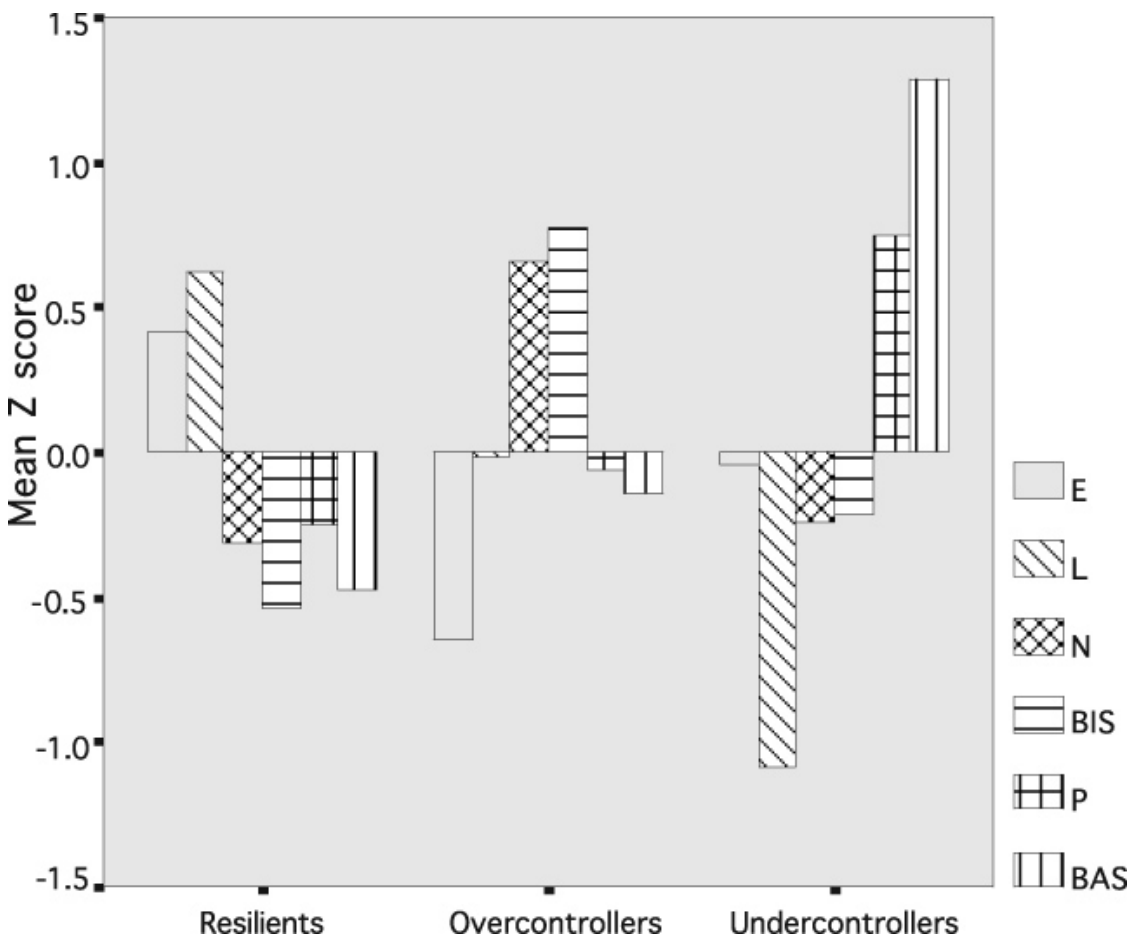

\section{Theory- and evidence-based self-esteem interventions: the way to success}

Bartholomew and colleagues have presented a protocol for the planning and development of theory- and evidence-based health promotion interventions that match target populations and intervention contexts (Bartholomew, Parcel, Kok, \& Gottlieb, 2001; 2006). This protocol, entitled Intervention Mapping (IM), guides health promoters through program development, demystifying the developmental process, and eliminating mistakes identified by previous teams. It provides health promoters with tools for applying theory and evidence during program development. It also provides a framework facilitating collaboration between researchers, health promoters, target populations and communities, and stakeholders. IM acknowledges that health is a function of individuals and their environments, including social networks, organisations, communities and public policy frameworks. IM regards decision-makers as agents in the environment who may serve as targets for health promotion interventions (Bartholomew et al., 2001; 2006). IM has now been used for a variety of health promotion programs and has shown to be effective in changing health behaviour (e.g., HIV prevention in youth; Schaalma et al., 1996) as well as prevention of mental health problems (e.g., stress prevention in youth; Kraag et al., 2005).

IM describes the process of promotion program development in six steps (figure 1). The design of health education and health promotion programs starts with needs assessments that are sensitive to the experiences of, and problems faced by, target populations. Before health promoters start thinking about interventions, they need to have a clear insight into health problems, the behavioural and environmental factors that cause these health problems. In addition, health promoters need to get to know their target populations and communities, their needs and their strengths and capacities. IM recommends local, collaborative development that is responsive to the particular needs of a population in a specified geographical, economic and cultural context. Needs assessments enable program developers to define intervention goals in terms of change in health status, quality of life, behaviour, and environmental conditions. Needs assessments provide the empirical basis of health promotion goals.

In the second phase of program development, health promoters specify the general program goals into proximal program objectives that explicate who and what will change as a result of the intervention. Proximal program objectives specify what individuals need to learn or what must be changed in the environment. They may refer to individual level change (e.g., adolescents report a significant reduction in discrepancies between their aspirations and their perceived adequacy), or, for instance, organisational level change (e.g., 'school administrators will acknowledge the advantages of school-wide rules against bullying'). In IM, the list of proximal objectives guides the selection of intervention methods. 
The third phase in IM concerns the selection of theorybased intervention methods that may be effective in accomplishing the proximal program objectives, and the translation of these methods into practical intervention strategies and materials. For instance, a theoretically based method for enhancing self-confidence in performing a particular behaviour is modelling or learning by observation (Bandura, 1986). A practical intervention strategy for this method could be role-playing and/or watching competent models on video. Theory-based intervention methods can be derived from the scientific literature. Information about the feasibility and effectiveness of practical intervention strategies can be derived from needs assessments, experiences with other programs, collaboration with program implementers and users, and from small-scale pilots. An important task in this step is the consideration of the conditions under which intervention methods and strategies can be effective. A method or strategy that has proven to be effective among a particular target group in a particular context will not necessarily be just as effective among other populations or in other contexts (Kok et al., 2004).

In IM step 4 program developers design a plan for the production and delivery of the program. This step involves organising the intervention strategies into a deliverable intervention program taking into account target groups and intervention settings, and producing and pilot testing the materials. Health promotion planners have to integrate separate strategies into one coherent program. They have to make decisions on the program structure, its scope, the sequence of strategies, and the communication channels. In this phase, planners usually collaborate with producers, such as text writers, graphic designers and video producers. The planners' major task is to convey program intent to producers, and to monitor whether final program products adequately incorporate the theoretical underpinning.

The production of the program must be closely linked to the planning of program adoption and implementation and reliable diffusion procedures are essential to program impact. IM step 5 describes how program developers can set objectives for program adoption, implementation and maintenance, and how they can link these objectives to theoretical methods and practical strategies for promoting program adoption and sustained implementation. Thus, health promoters not only need to develop interventions to change individual behaviour, but also interventions to facilitate program adoption, implementation and maintenance. Thinking about program adoption, implementation and maintenance is relevant from the very beginning of the planning process.

The last IM phase refers to the planning of process and effect evaluation. IM step 6 invites planners to develop an evaluation model that specifies evaluation levels, outcome indicators and measurement, and evaluation planning. The content of the evaluation model is based upon the previous IM steps. On the basis of the first two IM steps, the effect of evaluation questions can be specified. This enables health promoters to measure changes in proximal program objectives, health promoting behaviours and sub-behaviours, and even the health problem. On the basis of step 3 and 5 process evaluation questions can be developed. This enables health promoters to evaluate the reach of the program and the quality of its implementation.

\section{Concluding remarks: the road ahead}

The development of self-esteem interventions targeting children and adolescents is a complex process. Such selfesteem programs should be theory- and evidence-based and should be developed in close collaboration between intervention developers, social scientists, program implementers and users. Furthermore, developers should pay attention to implementation and evaluation of their intervention programs. In this article we have outlined the different steps of IM, a planning protocol for the development of theory- and evidence-based intervention programs (Bartholomew et al., 2001; 2006). In the past, many self-esteem interventions have not been theoryand evidence-based, whereas such programs have proven to be more effective in changing self-esteem in children and adolescents (Haney \& Durlak, 1998). Future selfesteem interventions may benefit from applying IM because it results in theory- and evidence-based interventions that are most likely to be effective.

With regard to the content of self-esteem interventions, IM builds on recent theoretical insights into selfesteem. Whereas many interventions in the past have focused on boosting global self-esteem, there is currently some debate about the adverse effects of increasing selfesteem levels in (some) youths (see Baumeister et al., 1996). It seems important to tailor intervention programs to the individual needs of participants. For instance, whereas it might be useful for youngsters with low selfesteem to emphasise the importance of areas in which they are skilful and discount the ones in which they are unsuccessful, this strategy seems inappropriate for children and adolescents with inflated levels of self-esteem.

Research in the past decade has demonstrated that self-esteem is a complex and multifaceted construct (Harter, 2003; Kernis, 2002). Future self-esteem interventions should therefore not only focus on global self-esteem, but also on domain-specific self-esteem. In addition, future self-esteem interventions should address other important 
aspects of self-esteem as well, such as self-esteem stability, contingent self-esteem and implicit self-esteem. Additional research is needed before succesful interventions targeting these other aspects of self-esteem can be developed. For example, it is still unclear how contingent self-esteem develops during childhood and adolescence. It seems important to make self-esteem in children and adolescents less contingent on outcomes and achievements. A way to diminish the negative consequences of the threat to self-esteem is to base one's self-esteem on different domains: if children fail to succeed in one particular domain, their self-worth can still be protected by success in other domains. Research on contingent selfesteem of children and adolescents should reveal if it is useful to incorporate such ideas in self-esteem interventions. Implicit self-esteem and its relationship to psychopathology also need to be investigated among children and adolescents. Recent research on implicit self-esteem in adults has demonstrated that it is possible to enhance implicit self-esteem through classical conditioning (Baccus, Baldwin, \& Packer, 2004) or by subliminal evaluative conditioning (Dijksterhuis, 2004). Future studies are needed to examine whether implicit self-esteem can also be enhanced in children and adolescents. If this were the case, this might provide opportunities for new selfesteem interventions for children and adolescents, for instance using computer games to enhance implicit selfesteem.

An important aspect of IM is program evaluation. Research on self-esteem interventions is urgently needed and should address two issues. First, since most interventions that have been evaluated only examined short-term effects, the sustainability of the effects of self-esteem interventions remains unclear (Emler, 2001). Future program evaluations should assess the long-term effects of self-esteem interventions. Second, it needs to be clarified why certain self-esteem interventions work. Interventions are often a mix of various strategies and it is unclear which aspects of the intervention are most effective (Emler, 2001). Experimental research is needed to investigate effective elements of self-esteem interventions. This information can be used in the development of future self-esteem interventions.

\section{References}

Baccus, J.R., Baldwin, M.W., \& Packer, D.J. (2004). Increasing implicit self-esteem through classical conditioning. Psychological Science, 15, 498-502.

Bandura, A. (1986). Social Foundations of Thought and Action: A Social Cognitive Theory. Englewood Cliffs, NJ: Prentice-Hall.

Bartholomew, L.K., Parcel, G., Kok, G., \& Gottlieb, N.H. (2001). Intervention mapping: Designing theory- and evidence-based health promotion programs. Mountain View, CA: Mayfield Publishing Company.

Bartholomew, L.K., Parcel, G.S., Kok, G., \& Gottlieb, N.H. (2006). Planning health promotion programs: an Intervention Mapping approach. San Francisco, CA: Jossey-Bass.

Baumeister, R.F., Smart, L., \& Boden, J.M. (1996). Relation of threatened egotism to violence and aggression: The dark side of high self-esteem. Psychological Review, 103, 5-33.

Beck, A.T., Brown, G.K., Steer, R.A., Kuyken, W., \& Grisham, J. (2001) Psychometric properties of the Beck Self-Esteem Scales. Behavior Research and Therapy, 39, 115-124.

Butler, R.J. \& Gasson, S.L. (2005). Self esteem/self-concept scales for children and adolescents: A review. Child and Adolescent Mental Health, 10, 190-201.

Crocker, J., \& Park, L.E. (2003). Seeling self-esteem: construction, maintenance, and protection of self-worth. In M. R. Leary and J. P. Tangney, Handbook of self and identity (pp. 291-313). New York: The Guilford Press.

Crocker, J., \& Wolfe, C.T. (2001). Contingencies of self-worth. Psychological Review, 108, 593-623.

DeHart, T., Pelham, B.W., \& Tennen, H. (2006). What lies beneath: Parenting style and implicit self-esteem. Journal of Experimental Social Psychology, 42, 1-17.

Donders, W., \& Verschueren, K. (2004). Zelfwaardering en acceptatie door leeftijdsgenoten. Een longitudinaal onderzoek bij basisschoolkinderen. Kind en Adolescent, 25, 74-90.

Dijksterhuis, A. (2004). I like myself but I don't know why: Enhancing implicit self-esteem by evaluative conditioning. Journal of Personality and Social Psychology, 86, 345-355.

Donnellan, M.B., Tresniewski, K.H., Robins, R.W., Moffitt, T.E., \& Caspi, A. (2005). Low self-esteem is related to aggression, antisocial behaviour, and delinquency. Psychological Science, $16,328-335$.

Emler, N. (2001). Self-esteem: The costs and causes of low selfworth. York: Joseph Rowntree Foundation.

Finkenauer, C., Engels, R.C.M.E., Meeus, W.S., \& Oosterwegel, A. (2002). Self and identity in early adolescence. The pains and gains of knowing who and what you are. In T.M. Brinthaupt \& R.P. Lipka (Eds)., Understanding early adolescent self and identity. Applications and interventions (pp. 25-56). Albany, NY: State University of New York Press.

Greenberg, J., Pyszczynski, T., \& Solomon, S. (1986). The causes and consequences for a need for self-esteem: A terror management theory. In R. F. Baumeister (Ed.), Public self and private self (pp. 189-212). New York: Springer-Verlag.

Greenwald, A.G., \& Banaji, M.R. (1995). Implicit social cognition: Attitudes, self-esteem, and stereotypes. Psychological Review, 102, 4-27.

Greenwald, A.G., \& Farnham, S.D. (2000). Using the implicit association test to measure self-esteem and self-concept. Journal of Personality and Social Psychology, 79, 1022-1038.

Haney, P., \& Durlak, J.A. (1998). Changing self-esteem in children and adolescents: A meta-analytic review. Journal of Clinical Child Psychology, 27, 423-433.

Harter, S. (1993). Causes and consequences of low self-esteem in children and adolescents. In R.F. Baumeister (Ed.), Selfesteem: The puzzle of low self-regard (pp. 87-116). New York: Plenum.

Harter, S. (1999). The construction of the self. A developmental perspective. New York: Guilford Press.

Harter, S. (2003). The development of self-representations during childhood and adolescence. In M. R. Leary and J. P. Tangney, Handbook of self and identity (pp. 610-642). New York: The Guilford Press.

Hoffman, W., Gawronski, B., Gschwendner, T., Le, H., \& Schmitt, M. (2005). A meta-analysis on the correlation between the 
implicit association test and explicit self-report measures. Personality and Social Psychology Bulletin, 31, 1369-1385.

Jansen, D.L., \& Vonk, R. (2005). Contingente zelfwaardering: betrouwbaarheid en validiteit van de Nederlandse globale en domeinspecifieke contingentieschaal. Nederlands Tijdschrift voor de Psychologie, 60, 1-14.

Kernis, M.H. (2002). Self-esteem as a multifaceted construct. In T. M. Brinthaupt \& R.P. Lipka (Eds)., Understanding early adolescent self and identity. Applications and interventions (pp. 5790). Albany, NY: State University of New York Press.

Kernis, M.H., \& Goldman, B.M. (2003). Stability and variability in self-concept and self-esteem. In M. R. Leary and J. P. Tangney, Handbook of self and identity (pp. 106-127). New York: The Guilford Press.

Kling, K.C., Hyde, J.S., Showers, C.J., \& Buswell, B.N. (1999). Gender differences in self-esteem: A meta-analysis. Psychological Bulletin, 125, 470-500.

Kok, G., Schaalma, H.P., Ruiter, R.A.C., Van Empelen, P., \& Brug, J. (2004). Intervention Mapping: A protocol for applying health psychology theory to prevention programmes. Journal of Health Psychology, 9, 85-98.

Kraag, G., Kok, G., Huijer Abu-Saad, H., Lamberts, P., \& Fekkes, M. (2005). Development of a stress management programmelearn young, learn fair - for fifth and sixth Formers in the Netherlands using Intervention Mapping. International Journal of Mental health Promotion, 7, 37-44.

Leary, M.R., \& MacDonald, G. (2003). Individual differences in self-esteem: A review and theoretical integration. In M.R. Leary and J.P. Tangney, Handbook of self and identity (pp. 401-420). New York: The Guilford Press.

Leary, M.R., \& Baumeister, R.F. (2000). The nature and function of self-esteem: Sociometer Theory. In M.P. Zanna (Ed), Advances in Experimental Social Psychology (Vol. 32, pp. 162). San Diego, CA: Academic Press.

Major, B., Barr, L., Zubek, J., \& Babey, S.H. (1999). Gender and self-esteem: A meta-analysis. In W. Swann \& J. Langlois (Eds. ), Sexism and stereotypes in modern society: The gender science of Janet Taylor Spence (pp. 223-253). Washington, DC: American Psychological Association.

Mann, M., Hosman, C.M.H., Schaalma, H.P., \& De Vries, N.K. (2004). Self-esteem in an broad-spectrum approach for mental health promotion. Health Education research, 19, 357-372.

Muris, P., Meesters, C., van de Blom, W., \& Mayer, B. (2005). Biological, psychological, and cultural correlates of body change strategies and eating problems in adolescent boys and girls. Eating behaviours, 6, 11-22.

Muris, P., Meesters, C., \& Fijen, P. (2003). The self-perception profile for children: Further evidence for its factor structure, reliability, and validity. Personality and Individual Differences, 35, 1791-1802.

Paradise, A.W., \& Kernis, M.H. (2002). Self-esteem and psychological well-being : Implications of fragile self-esteem. Journal of Social and Clinical Psychology, 21, 345-361.

Pyszczynski, T., Greenberg, J., Solomon, S., Arndt, J., \& Schimel, J. (2004). Why do people need self-esteem? A theoretical and empirical review. Psychological Bulletin, 130, 435-468.

Robins, R.W., Trzesniewski, K.H., Tracy, J.L., Gosling, S.D., \& Potter, J. (2002). Global self-esteem across the life span. Psychology and Aging, 17, 423-434.

Schaalma, H.P., Kok, G.J., Bosker, R., Parcel, G., Peters, L., Poelman, J., \& Reinders, J. (1996). Planned development and evaluation of AIDS/STD education for secondary school students in the Netherlands: Short-term effects. Health Education Quarterly, 23, 469-487.

Stice, E. (2002). Risk and maintenance factors for eating pathology: A meta-analytic review. Psychological Bulletin, 128, 825848.

Trzesniewski, K.H., Donnellan, B., \& Robins, R.W. (2003). Stability of self-esteem across the life span. Journal of Personality and Social Psychology, 84, 205-220.

World Health Organization (2004). Prevention of mental disorders. Effective interventions and policy options. Summary report. Geneva: World Health Organization. 